\title{
Intimate partner violence among HIV-positive service users of a tertiary care and treatment facility in Enugu State, Nigeria
}

Ifeoma M. Obionu, Chinwendu O. Echefu, Vina U. Chinweokwu, Winifred O. Chineme, Azodo U. Gabriel, Emmanuel N. Aguwa

University of Nigeria Teaching Hospital, Enugu, Nigeria

\begin{abstract}
Introduction: There have been growing concerns of intimate partner violence (IPV) in people living with HIV (PLHIV). The objective of this study was to determine the prevalence and predictors of IPV in PLHIV.

Material and methods: This was an analytical cross-sectional study carried out in Enugu State, Southeast Nigeria, among 360 PLHIV receiving care in a tertiary hospital. A systematic sampling method was used to select participants during clinic visits, and data was collected using a pretested questionnaire adapted from Nigerian demographic and health survey. Responses were based on incidents, which had occurred within a period of twelve months prior to the day of interview. $P$-values of $<0.05$ were considered statistically significant.

Results: The mean age of respondents was $35 \pm 5$ years. One hundred and eighty-nine (52.5\%) respondents had experienced a form of IPV in the last 12 months preceding the study. Being female and having a partner who uses illicit drugs or alcohol were found to be predictors of IPV $(\mathrm{AOR}=2.251,95 \% \mathrm{CI}: 1.438-3.522)$ and $(\mathrm{AOR}=1.467,95 \% \mathrm{CI}: 0.301-0.725)$, respectively.

Conclusions: Prevalence of IPV was high in respondents in this study and in light of these findings, there is need to facilitate IPV screening, counseling, and improve patient awareness of IPV in routine management of PLHIV in care and treatment facilities in Nigeria.
\end{abstract}

HIV AIDS Rev 2021; 20, 4: 275-280

DOI: https://doi.org/10.5114/hivar.2021.111896

Key words: intimate partner violence, HIV/AIDS, domestic violence.

\section{Introduction}

Intimate partner violence (IPV), historically called 'domestic violence', refers to victimization of a person with whom an abuser has or has had an intimate, romantic, or spousal relationship [1, 2]. IPV encompasses violence against both men and women, and typically involves physical harm, sexual assault, or fear of physical harm. It can include physical and sexual abuse, emotional abuse, economic

Address for correspondence: Ifeoma M. Obionu,

University of Nigeria Teaching Hospital, Enugu, Nigeria,

e-mail: ifeomaobionu@gmail.com

abuse, coercion and threats, intimidation, isolation, jealousy, and blame [3].

The issue of IPV has become a global concern and has been on the rise in developing countries [4]. General perception of IPV used to be that of a female victim and a male perpetrator. However, this perception is gradually being adjusted to expose the increasing trend of a female perpetrator and a male victim, or a male-male or female-female victim

Article history:

Received: 30.07.2020

Received in revised form: 07.09.2020

Accepted: 30.03.2021

Available online: 30.11 .2021
International Journal of HIV-Related Problems

HIV \& AIDS

R e v i e w 
and perpetrator [5]. There are many consequences of IPV, which may lead to sexual and reproductive health problems for women, sexually transmitted infections, including human immunodeficiency virus (HIV), pelvic inflammatory disease, urinary tract infections, and sexual dysfunction. IPV can have an effect on decision-making and negotiation in contraceptive or condom use with sexual partners [6], and lead to increased rates of depression, drugs and substance abuse, risky sexual behaviors, and increased risk of developing chronic diseases, such as coronary artery disease and hypertension [7].

There is a heavy burden of intimate partner violence and HIV globally, which coincide with a growing prevalence of mental health problems in Africa [8]. Additionally, there has been an increased awareness of a relation of IPV and HIV/ AIDS, explained by biological as well as socio-cultural and economic factors [9]. HIV infection and IPV remain highly sensitive areas that include stigmatization in many African countries. However, the exact relationship between HIV and IPV is complex and characterized by multiple points of interaction, by which IPV increases the risk of HIV infection and positive HIV status can lead to victimization [6].

Research has shown that the prevention of intimate partner violence is the key in the spread of HIV infection, and factors associated with onset of IPV among HIV-infected individuals indicate that violence often occurs after HIV status disclosure. Moreover, IPV is more likely to occur among people with HIV-positive partners than HIV-negative/ unknown status partners $[6,10]$. It has also been recognized as one of the important predictors of poor outcomes for people living with HIV (PLHIV) by affecting drug adherence, retention to care, mental health, quality of life, and adherence to follow-up, all of which lead to more hospitalizations and worsening of disease condition [11].

In Nigeria, women living with HIV/AIDS represent a more vulnerable group for IPV, and the impact on them is more severe in terms of psychological, physical, and pathological consequences; it may delay or prevent HIV testing and HIV status disclosure to partner [12]. Family disputes are often not perceived as violations of civil rights and usually are not reported to law enforcement agents. There is a reluctance to address this issue, given that it concerns of what has traditionally been viewed as a highly personal and sensitive aspect of family life [13]. While most of research in this area has focused on women, it has also been noted that IPV and adverse clinical outcomes have also been observed among men living with HIV, and the lifetime prevalence of IPV has been found to be $29 \%$ among men in general population, compared with $36 \%$ of that among women [14, 15].

The primary aim of the study was to determine the prevalence and predictors of IPV among people living with HIV attending a tertiary clinic in Enugu State, Nigeria.

\section{Material and methods}

This was an analytical cross-sectional study carried out in Enugu State, Southeast Nigeria among PLHIV receiving care in a tertiary hospital in 2019. In the Southeast part of Nigeria, there are two antiretroviral treatment (ART) referral centers, which are tertiary hospitals and are both owned by the government. The facility selected for this study serves as the major referral antiretroviral treatment center for PLHIV in the Southeast part of the country, and offers comprehensive HIV treatment and care services. The ART clinic is open four times a week by resident doctors, medical specialists, nurses, pharmacists, and counselors. It provide services, such as prevention of mother-to-child transmission (PMTCT) services, pediatric and adult HIV/AIDS treatment and care, and facility-based support group facilities, with nearly 150 patients attending the clinic daily.

The study was carried out among 360 PLHIV receiving care at the facility. Sample size was determined using sample size estimation formula for cross-sectional studies, and IPV prevalence of $75 \%$ obtained from a similar study was adapted $[16,17]$. Respondents of 18 years and above, with known HIV status for at least 12 months, and having an intimate partner within the last 12 months were included in the study, while those who were too ill were exempted from participation.

Data were collected using a systematic sampling method. Outpatient daily attendance registers formed a sampling frame, from which participants were selected daily. The first participant was selected from a random starting point. A sampling interval was calculated, and every third patient who met the inclusion criteria was selected. Participants were recruited during their clinic visits until the sample size was achieved. Ethical permit for the research was acquired from ethics committee of the University of Nigeria Teaching Hospital, and verbal informed consent was obtained from each study participant.

Data were gathered using a pre-tested semi-structured self-administered questionnaire adapted from a Nigerian demographic health survey [3], and questions asked were based on incidents within the last 12 months preceding the study. These responses were self-reported and involved recall of events in the last 12 months, and therefore were prone to recall bias.

An answer of 'Yes' to any of the questions on physical, psychological, or sexual violence meant that the respondent had experienced IPV. In this study, intimate partner violence (IPV) was defined as any behavior in an intimate relationship that caused physical, psychological, or sexual harm to those in that relationship [18].

Data were entered and analyzed using Epi Info, version 6. Results were presented as tables and cross-tabulations. $\chi^{2}$ and regression analysis was used to test for significance, and a level of statistical significance was set at $p<0.05$. Regression analysis was carried out to determine the predictors of IPV among the study population at a $95 \%$ confidence interval.

\section{Results}

A total of 360 respondents were included in the study. One hundred and twenty respondents $(33.3 \%)$ were males, while $240(66.6 \%)$ were females. The mean age of respondents was $35 \pm 5$ years. Most of the respondents had received a tertiary education $(n=163,45.3 \%), 178(48.3 \%)$ were married, and 197 (54.7\%) had children. 
Table 1. Socio-demographic characteristics of respondents $(N=360)$

\begin{tabular}{|c|c|}
\hline Factor & $n(\%)$ \\
\hline \multicolumn{2}{|l|}{ Gender } \\
\hline Male & $120(33.3)$ \\
\hline Female & $240(66.6)$ \\
\hline \multicolumn{2}{|l|}{ Age (years) } \\
\hline $18-35$ & $206(57.2)$ \\
\hline $36-55$ & $137(38.1)$ \\
\hline$>55$ & $17(4.7)$ \\
\hline \multicolumn{2}{|l|}{ Marital status } \\
\hline Single & $154(42.8)$ \\
\hline Married & $174(48.3)$ \\
\hline Divorced/separated & $23(6.4)$ \\
\hline Widowed & $9(2.5)$ \\
\hline \multicolumn{2}{|l|}{ Number of children } \\
\hline 0 & $162(45.0)$ \\
\hline $1-4$ & $159(44.2)$ \\
\hline$>5$ & $39(10.8)$ \\
\hline \multicolumn{2}{|l|}{ Level of education } \\
\hline None & $25(6.9)$ \\
\hline Primary & $39(10.8)$ \\
\hline Secondary & $133(36.9)$ \\
\hline Tertiary & $163(45.2)$ \\
\hline \multicolumn{2}{|l|}{ Religion } \\
\hline Christianity & $334(92.8)$ \\
\hline Islam & $22(6.1)$ \\
\hline Other & $4(1.1)$ \\
\hline \multicolumn{2}{|l|}{ Ethnic group } \\
\hline Igbo & $298(82.8)$ \\
\hline Yoruba & $25(6.9)$ \\
\hline Hausa & $23(6.4)$ \\
\hline Other & $14(3.9)$ \\
\hline \multicolumn{2}{|c|}{ Discovery of HIV-positive status } \\
\hline $1-5$ years & $257(71.4)$ \\
\hline $6-10$ years & $80(22.2)$ \\
\hline$>10$ years & $23(6.4)$ \\
\hline \multicolumn{2}{|l|}{ Partner's age } \\
\hline $18-35$ & $190(52.8)$ \\
\hline $36-55$ & $151(41.9)$ \\
\hline$>55$ & $19(5.3)$ \\
\hline \multicolumn{2}{|c|}{ Partner's use of illicit drugs and alcohol } \\
\hline Yes & $134(37.2)$ \\
\hline No & $226(62.8)$ \\
\hline
\end{tabular}

Table 1. Cont.

\begin{tabular}{l|c|}
\hline Factor & $n(\%)$ \\
\hline \multicolumn{2}{|l|}{ Partner's HIV status } \\
\hline \begin{tabular}{l|c}
\hline Positive & $171(47.5)$ \\
\hline Negative & $144(40.0)$ \\
\hline Do not know & $45(12.5)$ \\
\hline Disclosure of HIV status to partner \\
\hline Yes & $320(87.4)$ \\
\hline No & $40(11.1)$ \\
\hline
\end{tabular}
\end{tabular}

Most of the respondents $(n=169)$ have known their HIV status for about $2-5$ years $(46.9 \%)$ and $171(47.5 \%)$ had HIV-positive partners, while 45 participants (12.5\%) did not know their partner's HIV status (Table 1).

Majority ( $n=189,52.5 \%)$ of the respondents had experienced IPV within the last 12 months. One hundred and twenty-one $(33.7 \%)$ of the respondents reported that their partner had either insulted them or made them feel bad about themselves, $98(27.2 \%)$ indicated that their partner has said or done something to humiliate them in front of others, $37(10.3 \%)$ reported experiencing a threat or attack with a knife, gun, or any other weapon, and 72 (20.0\%) stated that their partner had physically forced them to have sexual intercourse against their will (Table 2).

The effects of IPV experienced by the respondents showed that 94 (26.1\%) of those who experienced IPV reported having thoughts of harming themselves and committing suicide, and 77 (21.4\%) feared for their lives and their children (Table 3).

Factors significantly associated with experience of IPV included being female $(p=0.000)$, being within the younger age range of 18-35 ( $p=0.003)$, and partner's use of illicit drugs and alcohol $(p=0.001)$ (Table 4$)$. Predictors of IPV were being female and partner's use of illicit drugs or alcohol. Females were about 2 times more likely to experience IPV than males (AOR $=2.251,95 \% \mathrm{CI}: 1.438-3.522)$, and those with partners using illicit drugs or alcohol were about 1.4 times more likely to experience IPV than those whose partners did not consume alcohol or illicit drugs $(\mathrm{AOR}=1.467$, 95\% CI: 0.301-0.725).

When respondents were asked about the action usually taken after experiencing violence, 70 (37.0\%) said they reported the incident, while 119 (62.9\%) did nothing. Most of the subjects reported the incidence mainly to relatives ( $n=58,82.9 \%$ ), while $6(8.6 \%)$ reported to the police and $6(8.6 \%)$ to other persons, such as religious leaders and friends.

\section{Discussion}

This study of IPV in people living with HIV was characterized by high levels of IPV ( $n=189,52.5 \%)$ in both men and women. Findings were similar to those of Pittsburg, USA, where approximately three quarters (73\%) of the sam- 
Table 2. Intimate partners' violence in respondents $(N=360)$

\begin{tabular}{l|c|}
\hline Type of violence & $n(\%)$ \\
\hline \begin{tabular}{l|} 
Psychological violence \\
\hline Partner has said or done something to humiliate me in front of others
\end{tabular} & $76(21.1)$ \\
\hline Partner has threatened to hurt or harm me or someone close to me & $121(33.6)$ \\
\hline Partner has insulted me or made me feel bad about myself & $72(20.0)$ \\
\hline Physical violence & $94(26.1)$ \\
\hline Partner has pushed me, shook me, or thrown something at me & $44(12.2)$ \\
\hline Partner has slapped me & $62(17.2)$ \\
\hline Partner has twisted my arm or pulled my hair & $74(20.6)$ \\
\hline Partner has punched me with his/ her fist or with something that could hurt me & $22(6.1)$ \\
\hline Partner has kicked me, dragged me, or beat me up & $37(10.3)$ \\
\hline Partner has tried to me or burn me on purpose & \\
\hline Partner has threatened or attacked me with a knife, gun, or any other weapon & $72(20.0)$ \\
\hline Sexual violence & $71(19.7)$ \\
\hline Partner has physically forced me to have sexual intercourse with him/her even against my will & $67(18.6)$ \\
\hline Partner has physically forced me to perform any other sexual acts I did not want to & $189(52.5)$ \\
\hline Partner has forced me with threats or in any other way to perform sexual acts I did not want to & \\
\hline Overall prevalence of IPV & \\
\hline
\end{tabular}

Table 3. Effect of intimate partners' violence on respondents

\begin{tabular}{l|c}
\hline Effect/consequences of IPV & $n(\%)$ \\
\hline Thoughts of harming self/ suicidal thoughts & $94(26.1)$ \\
\hline Poor compliance and missed medical appointments & $73(20.3)$ \\
\hline Physical damage (wounds, cuts, bruises, etc.) & $64(17.8)$ \\
\hline Fear for own and children life & $77(21.4)$ \\
\hline
\end{tabular}

ple reported life-time IPV, and 20\% reported current abuse; although study participants consisted of HIV men who had sex with men (MSM) [17], who were not part of the population studied in this research. IPV was statistically significantly higher in women living with HIV (59.2\%) than men (39.2\%). This finding was not surprising, as IPV has been found to be a problem commonly occurring among women [17], and research has shown that gender is a prominent risk factors for IPV, with women being disproportionately affected when compared to men [6]. This finding was confirmed in the present study, where being female was a predictor of IPV, and females were found to be about 2-time more likely to experience IPV than males (OR $=2.251,95 \% \mathrm{CI}: 1.438-3.522)$. However, in the current study, 39.2\% of men experienced IPV. In similar studies, IPV prevalence of 39\% [19] in men living with HIV/ AIDS showed that it is becoming more common for men to be victims of IPV. In a national crime victimization and safety survey in 2013 [20], the prevalence of IPV in the general population of Nigeria was $30 \%$, while in Southeastern part of Nigeria, it was $43 \%$. According to a Nigeria demographic and health survey carried out in 2018 [21], the prevalence of IPV in women in the general population was found to be $30 \%$. All findings were notably less than the prevalence of IPV in PLHIV found in this study, indicating an increased vulnerability of PLHIV to IPV.

These results highlight the importance of regular IPV risk assessments in both men and women living with HIV whenever they present to treatment facility, and the need to provide support. Partners' use of illicit drugs and alcohol was also positively associated with IPV, which was also expected, as similar study has confirmed factors associated with IPV in both HIV-exposed and non-exposed populations [22].

The effects of IPV, as revealed in this study, ranged from physical to mental health problems, which may be intensified due to the double burden of experiencing IPV while living with HIV. Some of the respondents in this study who had experienced IPV, reported that the experience had caused them to have thoughts of harming themselves and committing suicide; some feared for their lives and their children, and some had physical damage, such as cuts and bruises. It was also discovered in this study that most respondents had experienced all three forms of IPV, and similar findings have shown that experiencing more 
Table 4. Factors associated with experience of intimate partners' violence

\begin{tabular}{|c|c|c|c|c|c|c|}
\hline \multirow[t]{2}{*}{ Factor } & \multicolumn{2}{|c|}{ IPV present, $n=189$} & \multicolumn{2}{|c|}{ IPV absent, $n=171$} & \multirow[t]{2}{*}{$\chi^{2}$} & \multirow[t]{2}{*}{$p$-value } \\
\hline & $n$ & $\%$ & $n$ & $\%$ & & \\
\hline \multicolumn{7}{|l|}{ Gender } \\
\hline Male & 47 & 39.2 & 73 & 60.8 & \multirow[t]{2}{*}{12.832} & \multirow[t]{2}{*}{$0.000^{*}$} \\
\hline Female & 142 & 59.2 & 98 & 40.8 & & \\
\hline \multicolumn{7}{|l|}{ Marital status } \\
\hline Single & 81 & 52.6 & 73 & 47.4 & \multirow[t]{4}{*}{0.923} & \multirow[t]{4}{*}{0.820} \\
\hline Married & 90 & 51.7 & 84 & 48.3 & & \\
\hline Divorced/separated & 14 & 60.9 & 9 & 39.1 & & \\
\hline Widow/widower & 4 & 44.4 & 5 & 55.6 & & \\
\hline \multicolumn{7}{|l|}{ Age } \\
\hline $18-29$ & 74 & 61.7 & 46 & 38.3 & \multirow[t]{5}{*}{15.824} & \multirow[t]{5}{*}{$0.003^{*}$} \\
\hline $30-39$ & 69 & 56.6 & 53 & 43.4 & & \\
\hline $40-49$ & 33 & 40.2 & 49 & 59.8 & & \\
\hline $50-59$ & 7 & 28.0 & 18 & 72.0 & & \\
\hline$>60$ & 6 & 54.5 & 5 & 45.5 & & \\
\hline \multicolumn{7}{|l|}{ Level of education } \\
\hline None & 12 & 60.2 & 82 & 39.8 & \multirow[t]{4}{*}{2.189} & \multirow[t]{4}{*}{0.534} \\
\hline Primary & 17 & 43.6 & 22 & 56.4 & & \\
\hline Secondary & 69 & 51.9 & 64 & 48.1 & & \\
\hline Tertiary & 91 & 55.8 & 72 & 44.2 & & \\
\hline \multicolumn{7}{|l|}{ Presence of children } \\
\hline Yes & 101 & 51.3 & 96 & 48.7 & \multirow[t]{2}{*}{0.264} & \multirow[t]{2}{*}{0.607} \\
\hline No & 88 & 54.0 & 75 & 46.0 & & \\
\hline \multicolumn{7}{|l|}{ Partner's age } \\
\hline $18-29$ & 38 & 42.2 & 52 & 57.8 & \multirow[t]{4}{*}{6.037} & \multirow[t]{4}{*}{0.916} \\
\hline $30-39$ & 75 & 57.7 & 55 & 42.3 & & \\
\hline $40-49$ & 47 & 52.8 & 42 & 47.2 & & \\
\hline $50-59$ & 20 & 54.1 & 17 & 45.9 & & \\
\hline \multicolumn{7}{|l|}{ Partner's HIV status } \\
\hline Positive & 98 & 57.3 & 73 & 42.7 & \multirow[t]{3}{*}{3.347} & 0.188 \\
\hline Negative & 71 & 49.3 & 73 & 50.7 & & \\
\hline Do not know & 20 & 44.4 & 25 & 55.6 & & \\
\hline Disclosure of HIV-positiv & us to & & & & & \\
\hline Yes & 179 & 54.9 & 147 & 45.1 & 8.026 & 0.006 \\
\hline No & 10 & 29.4 & 25 & 70.6 & & \\
\hline Partner's usage of illicit & /alcoh & & & & & \\
\hline Yes & 86 & 64.2 & 48 & 35.8 & 11.675 & $0.001^{*}$ \\
\hline No & 103 & 45.6 & 123 & 54.4 & & \\
\hline Knowledge of partner's & atus & & & & & \\
\hline Yes & 169 & 53.7 & 146 & 46.3 & 1.338 & 0.247 \\
\hline No & & & & & & \\
\hline
\end{tabular}


than one type of abuse increases probability of having depressive symptoms and severity of the symptoms experienced. Depression is known to have adverse effects on HIV-related outcomes; there is a substantial evidence that depression reduces adherence to anti-retroviral medication $[23,24]$.

Most people especially women, who experience IPV do not seek help or support, and as seen in this study, only few respondents reported the incident, while others do nothing. Most respondents who have ever reported the incident, they reported to relatives, while very few reported to the police and other persons, such as religious leaders or friends. A review of literature also found that IPV was considered a normal part of marital relationships and was justified by $41-90 \%$ of female respondents. In developing countries, it is believed that a woman is the property of husband, and there is failure of authorities to treat sexual violence as a criminal offence, hence discouraging reporting on sexual violence [25].

\section{Conclusions}

Findings from this study revealed a high prevalence of IPV in PLHIV, and both women and men are affected by IPV. In light of these findings, there is a need to introduce routine IPV screening into day-to-day management of people living with HIV, ensuring appropriate counseling and referral services made available for affected individuals as well as improving patients' IPV awareness.

\section{Conflict of interest}

The authors declare no conflict of interest.

\section{References}

1. Barkley Burnett L. Domestic Violence: Background, Pathophysiology, Epidemiology [Internet]. 2018. Available from: https://emedicine. medscape.com/article/805546-overview (Accessed: 16.08.2018).

2. National Institute of Justice. Intimate Partner Violence [Internet]. 2017. p. 4. Available from: https://www.nij.gov/topics/crime/intimate-partner-violence/Pages/welcome.aspx (Accessed: 20.08.2018).

3. National Population Commission. Nigeria demographic and health survey [Internet]. National Population Commission. Federal Ministry of Health; 2013. p. 59. Available from: http://scholar.google. com/scholar?hl=en\&btnG=Search\&q=intitle:Nigeria+Demographic+And+Health+Survey\#0.

4. Iman'Ishimwe Mukamana J, Machakanja P, Adjei NK. Trends in prevalence and correlates of intimate partner violence against women in Zimbabwe, 2005-2015. BMC Int Health Hum Rights 2020; 20: 2. DOI: 10.1186/s12914-019-0220-8.

5. Howe TR. Marriages \& Families in the $21^{\text {st }}$ Century: a Bioecological Approach [Internet]. Wiley-Blackwell; 2012. p. 44. Available from: https://books.google.com.ng/books?hl=en\&lr=\&id=tcRJ4VpjE2MC\&oi $=$ fnd\&pg $=$ PR15\&dq $=$ Howe + TR.+ Families + in + crisis: + violence,+abuse,+and+neglect:+intimate+partner+violence:+marital+ rape. + In+Howe+TR. + Marriages+and+families $+\mathrm{in}+$ the $+21 \mathrm{st}+\mathrm{cen}-$ tury,+a+bioecological+appro (Accessed: 16.08.2018).

6. World Health Organization. Understanding and addressing violence against women [Internet]. 2012. p. 12. Available from: https:// www.who.int/reproductivehealth/topics/violence/vaw_series/en/ (Accessed: 26.11.2019).
7. Schafer KR, Brant J, Gupta S, et al. Intimate partner violence: a predictor of worse hiv outcomes and engagement in care. AIDS Patient Care STDS 2012; 26: 356-365.

8. Frew PM, Parker K, Vo L, et al. Socioecological factors influencing women's HIV risk in the United States: qualitative findings from the women's HIV SeroIncidence study (HPTN 064). BMC Public Health 2016; 16: 803.

9. The global coalition on women and AIDS. Violence Against Women and HIV/AIDS: Critical Intersections-Intimate Partner Violence and HIV/AIDS, Where and how do intimate partner violence and HIV/AIDS intersect? [Internet]. 2010. Available from: http:// www.who.int/hac/techguidance/pht/InfoBulletinIntimatePartnerViolenceFinal.pdf (Accessed: 16.08.2018).

10. Campbell JC, Baty ML, Ghandour RM, Stockman JK, Francisco L, Wagman J. The intersection of intimate partner violence against women and HIV/AIDS: a review. Int J Inj Contr Saf Promot 2008; 15 : 221-231.

11. Siemieniuk RAC, Krentz HB, Gill MJ. Intimate partner violence and HIV: a review. Curr HIV/AIDS Rep 2013; 10: 380-389.

12. UNAIDS. Report on the global AIDS epidemic [Internet]. 2010. Available from: http://files.unaids.org/en/media/unaids/contentassets/documents/unaidspublication/2010/20101123_globalreport_ en\%5B1\%5D.pdf (Accessed: 16.08.2018).

13. Iliyasu Z, Abubakar IS, Babashani M, Galadanci HS. Domestic violence among women living with HIV/AIDS in Kano, Northern Nigeria. Afr J Reprod Health 2011; 15: 41-50.

14. Black M, Basile K, Breiding M, et al. National Intimate Partner and Sexual Violence Survey: 2010 Summary Report. Centers for Disease Control and Prevention (CDC) 2011, p. 28

15. Bryan N, Davidov DM, Dick T, Bassler J, Fisher M. Intimate partner violence experiences among men living with HIV in rural appalachia. AIDS Behav 2019; 23: 3002-3014.

16. Onwasigwe CN. Principles and Methods of Epidemiology. $2^{\text {nd }}$ ed. Enugu: EL 'Damak Publications; 2010, p. 147.

17. Ramachandran S, Yonas MA, Silvestre AJ, Burke JG. Intimate partner violence among HIV-positive persons in an urban clinic. AIDS Care 2010; 22: 1536-1543.

18. Patra P, Prakash J, Patra B, Khanna P. Intimate partner violence: wounds are deeper. Indian J Psychiatry 2018; 60: 494-498.

19. Bryan N, Davidov DM, Dick T, Bassler J, Fisher M. Intimate partner violence experiences among men living with HIV in rural Appalachia. AIDS Behav 2019; 23: 3002-3014.

20. CLEEN Foundation. Public Presentation of Findings of the National Crime Victimization and Safety Survey [Internet]. 2013. Available from: http://new.cleen.org/Text Report of 2013 NCVS Findings. pdf (Accessed: 30.07.2020).

21. National Population Commission (NPC). Nigeria Demographic Health Survey 2018. $1^{\text {st }}$ ed. Abuja: Federal Ministry of Health; 2019, p. 32.

22. Obi SN, Ozumba BC. Factors associated with domestic violence in south-east Nigeria. J Obstet Gynaecol (Lahore) 2007; 27: 75-78.

23. Mitchell J, Wight M, Van Heerden A, Rochat TJ. Intimate partner violence, HIV, and mental health: a triple epidemic of global proportions. Int Rev Psychiatry 2016; 28: 452-463.

24. Dillon G, Hussain R, Loxton D, Rahman S. Mental and physical health and intimate partner violence against women: a review of the literature. Int J Family Med 2013; 2013: 313909. DOI: $10.1155 / 2013 / 313909$.

25. Li Y, Marshall CM, Rees HC, Nunez A, Ezeanolue EE, Ehiri JE. Intimate partner violence and HIV infection among women: a systematic review and meta-analysis. J Int AIDS Soc 2014; 17: 18-45. 